\title{
ALTERNATIVA ZERO: APRENDIZAGEM. REVISÃO DA OBRA PARA UMA TEORIA DA EDUCAÇAO DE JEROME S. BRUNER
}

\author{
Nobre, $\mathbf{S}$. \\ Doutorada em Psicologia \\ Universidad de Extremadura \\ sofianobre.psi@gmail.com \\ Vicente Castro, $\mathbf{F}$. \\ Catedrático de Psicología \\ Universidad de Extremadura \\ Reis, $\mathbf{S}$. \\ Psicóloga Clínia e Educaional no Ministério da Educação \\ Vicente, L \\ Psicóloga no Centro de Investigação da Clínica Delicate Age Saúde
}

Fecha de Recepción: 7 Julio 2019 Fecha de Admisión: 25 Septiembre 2019

\section{RESUMO}

0 ser humano obrigatoriamente pela sua condição humana mutável, evolutiva (ou involutiva), não somente aprende a fazer face aos condicionalismos e desafios da vida como os evita ou se defende deles.

As estratégias e mecanismos inatos e aprendidos não se apresentam pois em pontos contínuos ou isolados, serão antes função de várias equações a várias variáveis, ora resultando em planos convergentes ora divergentes, ora o mesmo ser humano lida ou se defende.

A pertinência deste artigo prende-se com a necessidade de questionar os modelos de aprendizagem, desenhando a Alternativa Terapêutica ilustrada pela primordial distinção dos processos fundamentais à aprendizagem: lidar com e defender-se de, que segundo Bruner (66), embora exista sempre um determinado grau de defesa, à excepção do psicótico depauperado, existe sempre uma determinada capacidade para lidar com um problema, pois até 0 esquizofrénico mais agudo consegue geralmente lidar com uma emergência grave.

Palavras-Chave: Bruner; teoria da educação; aprendizagem; lidar; defesa.

\section{ABSTRACT}

Alternative Zero : Learning. A revision of Jerome S. Bruner's to a theory of education. The Human being by his mutable, evolutive (or involutive) human condition, obligatorily, not only learn to face the constraints and challenges of life, as to avoid it or to defend from it.

Innate and learned mechanisms and strategies aren't just represented by continuos or isolated points, but mostly represented by a function of diverse equations with diverse variables, resulting on convergent planes, as well divergent planes, meaning the same human being sometimes copes with other defends from. 
The relevance of this paper comes from the necessity of questioning the learning models, drawing a Therapeutical Alternative ilustrated by the essential distinction of the primary processes to learning : cope with and defend from, as Bruner (66) explains that although exists always some defense level, excepted the depleted psychotic, exists always some hability to cope with a problem, as even the most severe schizophrenic can generaly cope with a substantial emergency.

Keywords : Bruner ; theory of education ; learning ; cope ; defense.

\section{CONSIDERAÇ̃̃ES PRÉVIAS}

Bruner (66) tomou como primeiro objecto de reflexão o conceito de normalidade humana para a sua Teoria de Educação. É pois relevante o seu significado, dado levantar várias questões, esta tentativa de definir um ser humano, objecto complexo, versátil, em constante mutação, assente em processos superiores de racional emocionalidade, ou emotiva racionalidade, parafraseando Damásio: tirem ao homem a emoção que tereis alguém incapaz de pensar; em que o jogo dos contrastes é apanágio de humanidade, jogo esse fomentado pelos aparelhos consciente e inconsciente, tanto de coerências como de inconsistências.

Um homem, um conflito, uma perpétua iminente vulnerabilidade à perturbação, um dilema de definição.

Normalé pois um constrangimento científico, só passível de definição enquanto distinção, embora ténue, entre estado psicológico saudável e doente.

E neste contexto de fronteira ténue entre saúde e doença, Bruner (66) elucida-nos sobre uma das mais importantes diferenças entre saúde e doença: a diferença entre lidar come defender-se de e suas inerentes consequências na vida mental do ser humano.

Lidar comé descrito como a capacidade de respeitar a nossa integridade enquanto seres humanos em interacção harmoniosa com o meio, em coerência ou equilíbrio com os nossos valores, desejos, sonhos, objectivos.

Já a defesa é um mecanismo de evitação do problema assumido como fonte de disfunção, desequilíbrio.

\section{ALTERNATIVA ZERO: APRENDIZAGEM}

0 estudo de Bruner (66) elaborado com crianças ditas normais e crianças com "bloqueio de aprendizagem", de inteligência normal ou superior, sem outras perturbações comportamentais, porém incapazes de aprender na escola, fez emergir a necessidade de distinguir estes dois processos: Lidar e Defesa.

Para Bruner (66) aprender é quase involuntário, quase todas as crianças têm os seus motivos intrínsecos para aprender. De tal forma que uma criança pode brincar (aprender) até à morte.

Qualquer aprendizagem tem como objectivo o domínio da actividade, de tal forma que a aprendizagem de actividades semelhantes resulta redundante, desnecessária. Qualquer aprendizagem é passível de generalização, de outra forma, estar-se-ia refém das tentativas-erro, em incansável questionamento de causa-efeito, inviabilizando a natural evolução. 0 estudo da efectividade da aprendizagem assenta na aplicação do conhecimento aprendido no passado, no presente, ou seja, na transferência da aprendizagem. (Bruner, 66)

Assim, tal como a nós, a Bruner (66) impôs-se-lhe a pergunta: que proveitos futuros se retiram, a mínimo esforço e sofrimento, com a experiência passada?

Era porém o esforço, segundo Bruner (66), dispendido na defesa às actividades de aprendizagem que inabilitava as crianças de aprender e a dificuldade advinha mais da incapacidade de lidar com as exigências do trabaIho escolar, ou de se defenderem do pânico e da ansiedade de desempenho, despoletados por essas exigências, do que propriamente dos problemas escolares. No entanto, ressalvou que a astúcia ou mestria requerida na "defensiva contra a aprendizagem" denunciava amplamente uma evidente capacidade de aprendizagem, ilustrada a posteriori na resolução criativa de problemas escolares, quando amenizados os pânicos.

0 crescimento intelectual, para (Bruner, 66), teria como determinantes seis elementos chave:

1) 0 facto de se caracterizar pela crescente independência da reacção relativamente à natureza imediata do estímulo;

2) de depender da interiorização de acontecimentos num "sistema de armazenamento"; 
3) implicar uma capacidade crescente de dizer a si e aos outros o que se fez ou vai fazer (auto-consciência);

4) depender de uma interacção sistemática e contingente entre um educador e um educando;

5) 0 facto de 0 ensino estar facilitado pela linguagem, que acaba por ser não apenas o meio de intercâmbio, mas também 0 instrumento que o próprio aluno pode depois utilizar para estabelecer ordem no ambiente, combinar experiências, organizar pensamentos sobre as coisas; e

6) o facto de ser marcado pela crescente capacidade de lidar simultaneamente com várias alternativas, de tratar de várias sequências durante o mesmo período de tempo e de dispensar tempo e atenção de modo conveniente a estas múltiplas exigências.

\section{SISTEMA DE REPRESENTAÇÃo}

De crucial importância é compreender o significado de representação: a forma como a criança se liberta dos estímulos presentes e conserva a experiência passada num modelo, e as regras que regem 0 armazenamento e a re-obtenção de informação deste modelo, o que significa portanto traduzir a experiência num modelo do mundo. 0 processo de aprendizagem, segundo Bruner (66), é um processo de aquisição de conceitos até à sua conceptualização, revela-se num primeiro momento através da acção, representação activa, como escreve Bruner (66), baseia-se na aprendizagem de respostas e formas de habituação; em segundo, pela representação icónica, regendo-se sobretudo por princípios de organização perceptual; por fim da representação simbólica, representação esta, por palavras ou linguagem como instrumento de pensamento, até à interiorização da linguagem, em que inicialmente a criança a usa como extensão do próprio gesto de apontar, e gradualmente é utilizada para significar objectos não presentes, mais tarde manipuladas gramaticalmente, como auxílio de resolução de problemas mentais, e mais tarde ainda, para categorização do possível, do condicional, do vasto domínio mental restante, sem qualquer referente directo na experiência imediata.

Como se transita de uma representação a outra é controverso, sucintamente, Bruner (66) diz que seria como se um tipo de formação de imagens ou de esquemas (dispositivo que torna uma sequência de acções simultânea, que a transforma numa representação imediata) surgisse automaticamente como um acompanhamento da estabilização da resposta, mas como o sistema nervoso converte uma sequência de respostas numa imagem ou esquema, está simplesmente por compreender.

Segundo Bruner (66), o desenvolvimento intelectual percorre estes três sistemas de representação até conseguir dominá-los, suspeitando que grande parte da nossa incómoda não-racionalidade, tanto nas formas destrutivas quanto nas valorosas, como as metáforas da poesia, derivam das nossas operações icónicas e activas sobre a experiência.

É certo que no domínio do último sistema de representação, segundo Bruner (66), quanto maior o conhecimento das propriedades da linguagem, maior o auxílio ao pensamento, convém aqui referir o processo do diálogo interno enquanto instrumento generoso do desenvolvimento intelectual.

Esta interiorização, nem sempre se elabora enquanto processo consciente, quer na criança quer no adulto, é manifestada, como ao longo dos tempos têm descrito artistas, enquanto veículos de expressão de sentimentos, pensamentos, tantas vezes não consciencializados senão após oportuno distanciamento e reinterpretação da catarse que a própria obra concretizara.

Diz Júlio Diniz, por exemplo, do poeta, que:

A poesia precisa de quem a faça e de quem a entenda, mas nem sempre quem a faz a entende nem quem a entende a consegue fazer.

Na grande maioria das vezes, mecanismos puramente inconscientes operam nas expressões artísticas, porquanto ser insensato, "desmontar" manifestações de arte, 0 artista será porventura, (ou sem ventura!) um adulto adverso à socialização mascarada de indiferença generalizada, que tal como a criança, sem consciência do que faz, do que cria. Tanto Ihes devemos às crianças e aos poetas, escultores, músicos e pintores, criadores, seres superiores, ou de supra-consciência, bem denunciada, na expressão do mais brilhante aforista, Óscar Wilde: 
Não é a arte que imita a natureza, é a natureza que imita a arte.

Pois então, no início do processo de desenvolvimento da aprendizagem da criança, inscreve-se a capacidade de representação activa, ou seja, a aprendizagem é mediada pela acção, em que "saber é principalmente saber fazer" (Bruner, 66); num segundo plano, as ideias coabitam o espaço das emoções e motivações (até aos onze anos as crianças podem bloquear, sempre que remetidas para espaços de pensamento ou idealização de objectos que não gostem ou receiem) e quando a aprendizagem se insere em contextos de conflito, seja como obtenção de aprovação ou amor dos pais, ou como agente provocador de rivalidade entre irmãos, torna-se carregada ou libidinizada, e estes laços afectivos que relacionam conceitos e ideias são frequentemente fortes e de difícil descongestionamento, evidenciando-se na escola. Sentimento, acção e pensamento entrelaçam-se, de tal forma que se podem atropelar, pois a compreensão de várias coisas ao mesmo tempo, na qual se toma a parte pelo todo ou o todo pela parte, o género pela espécie, o singular pelo plural ou vice-versa, como descrito pelo que na gramática se denomina sinédoque, os sentimentos e as acções podem representar coisas, as coisas, sentimentos e, as partes, totalidades, todavia em vez de atropelo, poderá emergir arte. Outro aspecto relevante é a incapacidade da criança pequena em adiar a gratificação, após a conclusão da tarefa a criança sente merecer a recompensa, sendoIhe alheio o estabelecimento de metas num futuro longínquo para colher a sua recompensa; a criança só concebe a aprendizagem enquanto efectuada por pequenos moldes, motivada extrinsecamente, ou seja, a aprendizagem é assente nas expectativas de recompensas externas, por isso mesmo controlada e moldada por elas, por tabus e proibições da esfera socializante. 0 factor externo como autoridade, seja fonte de recompensa ou punição, é portanto instável e perigoso, pois estruturas cognitivas carregadas são catalisadoras dos "pensamentos perigosos" da infância, e eventualmente das metáforas preventivas da actividade cognitiva defensiva. Pelo contrário, no caso da aprendizagem intrínseca, aprendizagem concebida enquanto fonte de auto-recompensa, portanto potenciada por uma genuína curiosidade e busca de competência (como ilustra o texto "A Vontade de Aprender"), potencia por sua vez uma "esfera do ego isenta de conflitos", o que se revela como óptima estratégia para a atitude positiva de lidar com, em vez da metáfora preventiva, estratégia de defesa ou evitamento.

Segundo Bruner (66), a efectiva aprendizagem na escola está intimamente ligada com três aspectos: em primeiro, desenvolver-se um sistema de organização cognitiva que separe os conceitos dos modos de acção que evocam; segundo, desenvolver-se uma capacidade que separe os conceitos, dos seus contextos afectivos; e em terceiro, desenvolver-se a indispensável capacidade de adiar a gratificação, de forma que os resultados das acções possam ser realmente tratados como informação, pilar de conhecimento, em vez de meros objectos de recompensa ou punição.

\section{A BRINCADEIRA}

A história inicial da criança é pois crucial, logo interessa reflectir sobre quatro aspectos fundamentais do crescimento da criança: a estimulação, a brincadeira, a identificação e um certo grau de ausência de impulso ou ansiedade.

Obviamente considerando os factores inerentes à aprendizagem, como as predisposições genéticas, pessoais, motivacionais, culturais e a identificação que representa um papel preponderante na construção do self da criança, pois a escolha de um modelo adequado é de primordial importância no seu desenvolvimento intelectual. Se a criança não reconhece competências ao modelo, o processo de aprendizagem torna-se conflituoso podendo ser dramático, pois a criança acaba por ficar com um ideal de competência rejeitado e portanto sem quem the oriente 0 crescimento.

Dado ser de extrema importância que a criança seja estimulada para além do processo mediado pela acção e da representação icónica, de imagética vulnerável ao vínculo afectivo, mas exposta a estimulação variada e de preferência sem tensões, a brincadeira, segundo Bruner (66), é o método propedêutico mais eficaz na aprendizagem, talvez o único capaz de assegurar à criança que os resultados da grande maioria de actividades não são graves ou serão menos graves do que a criança esperava ou temia. A brincadeira é assim um instrumento precioso na delimitação ou previsão das consequências dos seus actos, com as suas regras próprias como mais tarde é 
verificada na atitude de jogo. A brincar se experimentam estratégias, planos de acção, medidas de prevenção, e antecipação de resultados, ou seja, a brincar se aprende.

A vida como um jogo deve ser vivida, vivendo-se nesse jogo de luta pela sobrevivência, já sugerido pelo pensamento evolucionista do séc. XIX que a brincadeira permitiria ao organismo experimentar o seu repertório de respostas, como preparação para a questão posterior e mais séria de sobreviver às pressões do habitat, bem como, de luta pela excelência, expoente máximo do desenvolvimento intelectual, potenciadas pelo desenvolvimento da aprendizagem intrínseca, evidenciada pela extrema gratificação da auto-recompensa de fazer coisas por divertimento, como nos exemplifica Bruner (66), através do método de Niels Bohr (op cit Bruner, 66), ensinar a brincar, já que "há coisas tão importantes que só se pode brincar acerca delas".

Porém, um incentivo ou estimulação demasiado forte à aprendizagem, restringe-a, tornando a criança com menor capacidade de generalizar os conhecimentos adquiridos, pois uma aprendizagem dominada por recompensas e punições extrínsecas torna-se específica quanto ao que é requerido à actividade em causa; uma pressão constante não só bloqueia a criança como pode remetê-la aos processos primitivos da aprendizagem inicial, a tal ponto que a acção, 0 afecto e o pensamento se fundem numa metáfora preventiva, pelo que é exigível um certo grau de ausência de impulso e ansiedade, para garantir o saudável crescimento da criança.

\section{METÁFORA PREVENTIVA}

0 que é uma metáfora preventiva é a pergunta que se impõe, no momento.

É mais uma organização cognitiva complexiva que conceptual, centrando-se em conceitos afectivos, tais como, "coisas que podem magoar-me", objectos e situações aos quais são atribuídos significados carregados afectivamente, podendo ser exemplificado, pela rejeição da criança às fracções, pois sentidas como "números cortados", ou a operação algébrica de corte, que simboliza o acto de "matar números e letras de cada lado do sinal igual".

A metáfora preventiva, segundo Bruner (66) parece operar na criança bloqueada de duas maneiras: por assimilação, quando um objecto ou acontecimento é identificado com a metáfora preventiva defensiva, e assimilado às fantasias ou "manifestações", relacionadas com a metáfora, levando a criança a reagir ao objecto ou acontecimento de forma neurótica; e por negação, em que, mal um objecto ou acontecimento seja relacionado à metáfora é evitado, afastado da ideia, sobre-ignorado.

Tanto a assimilação como a negação defendem excessivamente, distraindo imenso, pois exigem uma contínua perscrutação do perigo no meio.

Existe porém outro factor a operar na distracção destas crianças, o facto de se sentirem condenadas quer se tiverem êxito (sofrem em casa sozinhas) quer se falharem (sofrem na escola e em casa). Estamos perante o dilema clássico, como o descreve Bruner (66) que ponta então três factores primordiais nas crianças vítimas deste dilema: a intensidade pura e simples, em que o dilema é tão agudo que despoleta um sistema defensivo drástico; a ausência de um modelo contingente, pois de facto a identificação parece fornecer a padronização que leva a criança a lidar com em vez de se defender de; e a falta de consciência da criança em relação ao que está a fazer.

\section{ALTERNATIVA TERAPÊUTICA}

Importa, desta feita, reflectir sobre a natureza da terapia, segundo Bruner (66) parece exigir bastante mais que um tratamento intrapsíquico de conteúdos inconscientes, que auxilie na contenção da actividade defensiva, assim como de sessões de orientação que ajudassem a criança a lidar com a aprendizagem, habilitando-a, antes de mais, a estabelecer uma situação de aprendizagem isenta de dilema, pois um orientador como apoio emocional, fomentava a aprendizagem intrínseca, a autopropulsão, nesse sentido a criança começaria a assumir o controlo e a obter uma sensação de recompensa, e o orientador como figura de identificação proporcionaria um novo modelo de lidar com, quer mostrando que os problemas eram solucionáveis e não eram perigosos, quer mostrando que embora não solucionáveis, não seriam fonte de desgraça ou punição. 
Assim a Psicologia deve retornar ao campo da educação (trave mestra da evolução humana) que hoje se processa através da invenção social, a Psicologia tem potencialidade para explorar o domínio da perfeição humana, mantendo animada na sociedade a percepção plena do que é possível, iluminando o caminho do ser humano, educando, mostrando, ilustrando, o que é possível fazer, ser e estar no mundo (salvaguardando que não deve haver nada mais insuportável que uma pessoa perfeita!), com audácia, para formular novas hipóteses, permitindo-nos um olhar novo e inocente, e humildade, para reconhecer aquilo que não compreendemos. (Bruner, 66)

\section{CONCLUSÕES}

Como conclusão Bruner (66) admite existir uma grande descontinuidade entre lidar com e a defesa, tanto nos objectivos como na natureza dos processos envolvidos.

A defesa dominada pela interpretação de perigo, livre dos processos conscientes, opera através da metáfora preventiva ilimitada. Para um crescimento saudável é imperioso desconectar acção, afecto e impulsos imediatos, dependendo este processo de se criarem, à criança, condições para o desenvolvimento da brincadeira, oferecendo um modelo de competência adequado, e de experiência da recompensa intrínseca, promovendo a "aprendizagem por aprendizagem", condições estas promotoras da capacidade essencial de lidar com.

Nesta ordem de ideias, Bruner (66) admite o romantismo pedagógico como instrumento da aprendizagem, em que os impulsos criativos da criança são despertados e contidos (acolhidos e transferidos) de forma a providenciar a necessária consciencialização e prazer.

0 sonho comandar a vida não é pois uma linda metáfora, mas uma expressão repleta de valores e ideais reflectidos, amadurecidos, sentidos dentro de alma, e com sentido consciente.

0 ser humano saudável equilibra, harmoniza, o que espera e 0 que alcança.

0 mundo é a balança; os pratos são 0 sonho e 0 desejo, a realização e a conquista; 0 ser humano é o pêndulo, vulnerável e oscilante, entre a satisfação e felicidade, e a frustração e tristeza.

Aprender é aceitar com destreza, a efémera condição de vida, a grandeza da balança gerida pela emoçãoesperança e razão-temperança.

Este Texto não obedece ao A090

\section{REFERÊNCIAS BIBLIOGRÁFICAS}

Banaschewski, T.; Ruppert, S.; Tannock, R.; Albrecht, B.; Becker, A. \& Uebel, H. (2006). Colour perception in ADHD. Journal Child Psychol Psychiatry, 47(6), pp.568-572. Popular.

Barros, D. (2007). Tecnologias de la inteligência: gestión de la competencia pedagógica virtual. Madrid:

Bruner, J.S. (1999). Para uma Teoria da Educação. (Trad. Manuela Vaz). Lisboa: Relógio D’Água Editores. (Obra original publicada em 1966) American Psychiatric Association (2014). DSM-V: Manual de diagnóstico e Cohen, L., Manion, L. \& Morrison, K. (2007). Research methods in education (6th Ed.). London: Routledge.

DSM V- (2013). Manual de Diagnóstico e Estatística das Perturbações Mentais. Lisboa: Climepsi Editores.

Dias, M. \& Chaves, J. (2000). Perceção visual e dificuldades de aprendizagem: um estudo com alunos do 1.- ciclo do ensino básico. Revista Galego-Portuguesa de Psicoloxía e Educación, Act Psicopedagogía. Vol.6, n.4. Corunha: Universidade da Corunha \& Braga: Universidade do Minho, pp.389-398.

Leij, A. \& Morfidi, E. (2006). Core deficits and variable differences in Dutch poor readers learning English. Journal Learn Disabilities, 39(1), pp.74-90.estatística das perturbações mentais (5ª Ed. Revista). Lisboa: Climepsi Editores.

Willcutt, G. \& Pennington, F. (2000). Psychiatric comorbidity in children and adolescents with reading disability. Journal of Child Psychology and Psychiatry, 41(8), pp.1039-1048. 